\title{
A STUDY ON THE EFFECTS OF VIEWING ANGLE VARIATION IN SUGARCANE RADIOMETRIC MEASURES
}

\author{
Estudo do efeito da variação no ângulo de visada em medidas radiométricas na \\ cana-de-açúcar \\ Érika Akemi Saito Moriya ${ }^{1}$ - ORCID:0000-0002-2784-9608 \\ Nilton Nobuhiro Imai ${ }^{1}$ - ORCID - 0000-0003-0516-0567 \\ Antonio Maria Garcia Tommaselli ${ }^{1}$ - ORCID - 0000-0003-0483-1103 \\ ${ }^{1}$ Universidade Estadual Paulista (Unesp), Departamento de Cartografia, Presidente Prudente-São \\ Paulo, Brasil. \\ E-mail: erikaasaito@gmail.com; nimai@fct.unesp.br; tomaseli@fct.unesp.br
}

Received in February 14 ${ }^{\text {th }}, 2017$.

Accepted in December 21 2017.

\section{Abstract:}

Remote Sensing techniques, such as field spectroscopy provide information with a large level of detail about spectral characteristics of plants enabling the monitoring of crops. The aim of this study is to analyze the influence of viewing angle in estimating the Bidirectional Reflectance Distribution Function (BRDF) for the case of sugarcane. The study on the variation of the spectral reflectance profile can help the improvement of algorithms for correction of BRDF in remote sensing images. Therefore, spectral measurements acquired on nadir and different off-nadir view angle directions were considered in the experiments. Change both anisotropy factor and anisotropy index was determined in order to evaluate the BRDF variability in the spectral data of sugarcane. BRDF correction was applied using the Walthall model, thus reducing the BRDF effects. From the results obtained in the experiments, the spectral signatures showed a similar spectral pattern varying mainly in intensity. The anisotropy factor which showed a similar pattern in all wavelengths. The visual analysis of the spectral reflectance profile of sugarcane showed variation mainly in intensity at different angles. The use of Walthall model reduced the BRDF effects and brought the spectral reflectance profiles acquired on different viewing geometry close to nadir viewing. Therefore, BRDF effects on remote sensing data of vegetation cover can be minimized by applying this model. This conclusion contributes to developing suitable algorithms to produce radiometrically calibrated mosaics with remote sensing images taken by aerial platforms.

Keywords: Spectral measure; Bidirectional reflectance distribution function; Anisotropy.

\section{Resumo:}

Técnicas de Sensoriamento Remoto, como a espectroscopia de campo fornecem informações mais detalhadas das características espectrais das plantas permitindo um melhor

How to cite this article: Moriya, E.A.S.; et al. A study on the effects of viewing angle variation in sugarcane radiometric measures. Bulletin of Geodetic Sciences, Vol. 24, issue 1, 85-97, Jan-Mar, 2018. 
acompanhamento da cultura. O objetivo deste trabalho é analisar a influência do ângulo de visada na estimativa da Função de Distribuição de Reflectância Bidirecional (FDRB) no caso da cana-deaçúcar. Nesse sentido, foram avaliadas as variações decorrentes da mudança no ângulo de visada e conforme a região do espectro eletromagnético. O estudo da variação das curvas espectrais permite auxiliar o desenvolvimento de algoritmos para correção da FDRB em imagens de sensoriamento remoto. Portanto, as medições espectrais em ângulos no nadir e fora do nadir foram consideradas nos experimentos. O fator de anisotropia e o índice de anisotropia foram determinados com o objetivo de avaliar a variabilidade do BRDF nos dados espectrais da cana-deaçúcar. Aplicou-se o modelo de correção da FDRB de Walthall para reduzir os efeitos da FDRB nas curvas espectrais. Os resultados obtidos demonstraram que as assinaturas espectrais apresentaram forma similar variando principalmente a magnitude. O fator de anisotropia evidenciou um comportamento similar em todos os comprimentos de onda, assim como na análise visual das curvas espectrais da cana-de-açúcar, apresentando principalmente variação na intensidade nos diferentes ângulos de visada. Utilizando modelos como o de Walthall é possível reduzir o efeito da FRDB nas curvas espectrais aproximando as curvas para o nadir. Portanto, os efeitos da FRDB que ocorrem nos dados de sensoriamento remoto da vegetação podem ser minimizados pelo modelo. Esta conclusão contribui para o desenvolvimento de algoritmos adequados para produzir mosaicos calibrados radiometricamente a partir de imagens de sensoriamento remoto adquiridas por plataformas aéreas.

Palavras-chave: Medidas espectrais; Função de distribuição de reflectância bidirecional; Anisotropia.

\section{Introduction}

Brazil is a world leader in the production and export of various agricultural products, and is the main producer of sugarcane (Unica 2008). Concern over the scarcity of fossil fuels has stimulated the policy of encouraging the production and use of biofuels, such as ethanol, contributing to the expansion of sugarcane farming in Brazil. The monitoring of sugarcane crop areas in the State of São Paulo is being carried out by Canasat with satellite images (Rudorff et al. 2010), a project of the National Institute of Space Research (INPE), in partnership with other institutions (INPE 2014). In the 2003/2004 harvesting period, Canasat estimated 3 million hectares of sugarcane crop area and in the crop of 2013/2014 an estimated 5.7 million hectares were estimated, evidencing the expansion of this crop in the State of São Paulo (INPE 2014).

The development of new methodologies for plantations monitoring, based on remote sensing, can contribute to the development of more robust calibration and reference models (Ahamed et al. 2011). Field spectroscopy uses sensors such as spectroradiometers, spectroscopes and radiometers, capable of quantifying the energy resulting from the interaction of electromagnetic radiation with the target. Depending on the type of instrument, spectral reflectance profile or images can be obtained under natural lighting conditions (Milton and Webb 1987). Remote sensing data can provide useful information that can be used for the acquisition of information from the crops, allowing a more detailed monitoring of the characteristics of the plant (Ahamed et al. 2011).

Lofton et al. (2012) emphasize the need for research to serve as a reference in relation to differences in the structure of sugarcane canopies. Although there are studies, such as Galvão et 
al. (2005), that have identified different varieties of sugarcane based on differences in canopy structure and spectral characteristics, it is necessary to observe other characteristics, such as leaf angle or leaf length, alongside other information. Which may offer a more accurate methodology to improve techniques for monitoring the sugarcane crop.

According to Galvão, Formaggio and Tisot $(2005,2006)$ there are differences in spectral response depending on the type of canopy architecture, showing that planophile canopy plants have higher reflectance than plants with erectile canopy, since the erectile canopies have a greater influence on the shading caused by the canopy components themselves, as well as the greater internal absorption of radiation, that affects the canopy. In addition, the architecture of erectile canopies favors the detection of straw, stalks and nodes within the canopy (Galvão, Formaggio and Tisot, 2005).

Knowledge about reflectance factors distributions and the physical principles is essential for utilizing radiometric measurements (Kimes et al. 1985). Spectral reflectance measurements are needed to understand the scattering properties of surfaces as a function of the optical properties and geometric structure of the scene components and the solar radiation interaction (Kimes, Smith and Ranson (1980). The Bidirectional Reflectance Distribution Function (BRDF) of natural targets affects the response recorded by aerial and orbital sensors (Sandmeier and Itten 1999), and it is necessary to have knowledge of its effect on the recorded values in order to treat and analyze the spectral response of the images taken by these sensors. The bidirectional effects are intrinsic and distinct from the characteristics of the sensed surfaces when affected by radiation (Sandmeier and Itten 1999).

In order to measure BRDF quantity, there is need to consider directional measurements in infinitesimal small solid angles and illumination from a single direction. A directional field of view (FOV) measurement is technically difficult to obtain a representative BDRF data (Sandmeier 2000). However, when measurements are taken with small FOV under clear sky conditions with predominantly direct radiation, these measured values are closely approximate use BRDF (Robinson and Biehl 1982; Sandmeier 2000). Sandmeier 2000 propose that small FOV can be with $2^{\circ}$ to consider an approximate bidirectional reflectance factors.

Anisotropy is a spectral property that shows whether a certain target is directionally dependent. There are models reported in the literature that consider the directional dependence of the targets and minimizes the bidirectional reflectance caused by viewing geometry (Liang 2004; Sandmeier et al. 1998). The more detailed knowledge of the anisotropy of the recorded reflectance factor of the vegetation canopy is important in the analysis and treatment of remote sensing data (Deering, Middleton and Eck 1994; Weyermann et al. 2014). Walthall et al. (1985) proposed a model to compensate the anisotropy factor in target response and minimized the effect of BRDF from vegetation based on normalized measurement in nadir.

The objective of this work was to analyze the effect of the BRDF of a given sugarcane canopy in radiometric measurements taken at different viewing angle geometry. The anisotropy factor and anisotropy index were determined in order to evaluate the BRDF variability in sugarcane canopy. The hypothesis was that Walthall et al. (1985) model is able to minimize the directional effects of sugarcane canopies. 


\section{Methodology}

To evaluate the variations of sugarcane radiometric measurements with changes in the viewing angle, a special mounting support was built to carry out the measurements over healthy sugarcane canopy. The study on the variation of the spectral reflectance profile can support improvements in the algorithms of anisotropy correction in images acquired by the sensor. Therefore, spectral measurements in nadir and off-nadir angles were considered in the experiments. Spectral measurements were performed, and the correlation coefficient was calculated to compare the spectral reflectance profile. The anisotropy factor and anisotropy index were determined to aim at the estimation of the BRDF variability in the spectral data of sugarcane. Finally, a model to minimize the BRDF effect was applied in the spectral reflectance profile. Figure 1 shows a flowchart summarizing the steps of the methodology adopted, which are detailed in this section.

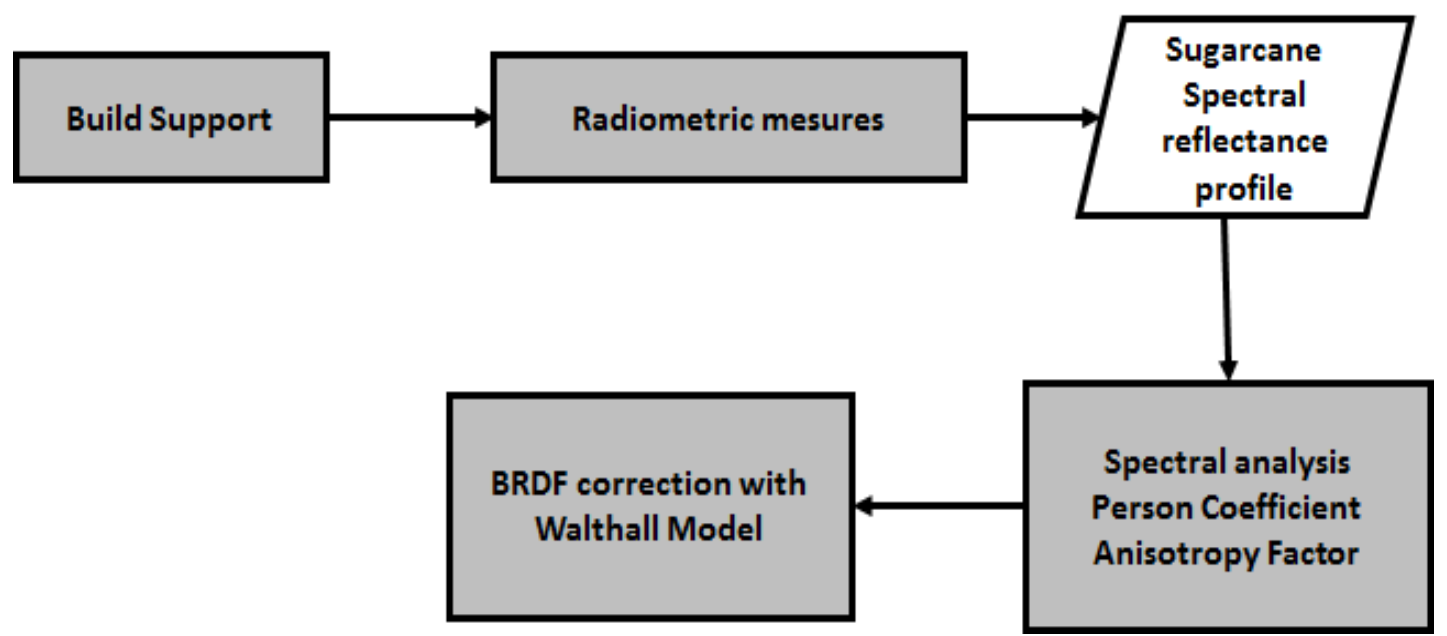

Figure 1: Flowchart of the methodology to evaluate the variations of sugarcane radiometric measurements with changes in the viewing angle.

In order to study the influence of the viewing angle on radiometric measurements for the estimation of HCRF in healthy sugarcane, measurements were performed in 03/17/2014 close to 11:00 am with an ASD FieldSpec ${ }^{\circledR}$ UV / NIR spectroradiometer, which covers a spectral band of $325 \mathrm{~nm}$ at $1075 \mathrm{~nm}$. The location where the measurements were taken has a latitude of $22^{\circ}$ $07^{\prime} 21.483$ "S and a longitude $51^{\circ} 24^{\prime} 27.187^{\prime \prime} \mathrm{W}$. In order to estimate the BRDF effects on the canopy, a small FOV (1 degree) in radiometric measurement instrument was considered. All measurements were taken under clear sky conditions and directly illumination of the sun. According to Robinson and Biehl (1982) and Sandmeier (2000) this geometry acquisition and solar illumination condition are needed to estimate the BRDF.

To perform the experiment, the forward scattering direction were considered in measurements, that is, shadowed components from a sensor perspective were taken into account. A wooden mount was built that integrated different sensors, so that both images and spectroradiometric measurements could be acquired simultaneously. The support has the capacity to couple two cameras and one spectroradiometer, however, in this case study only the spectroradiometer was used (Figure 2.A). 

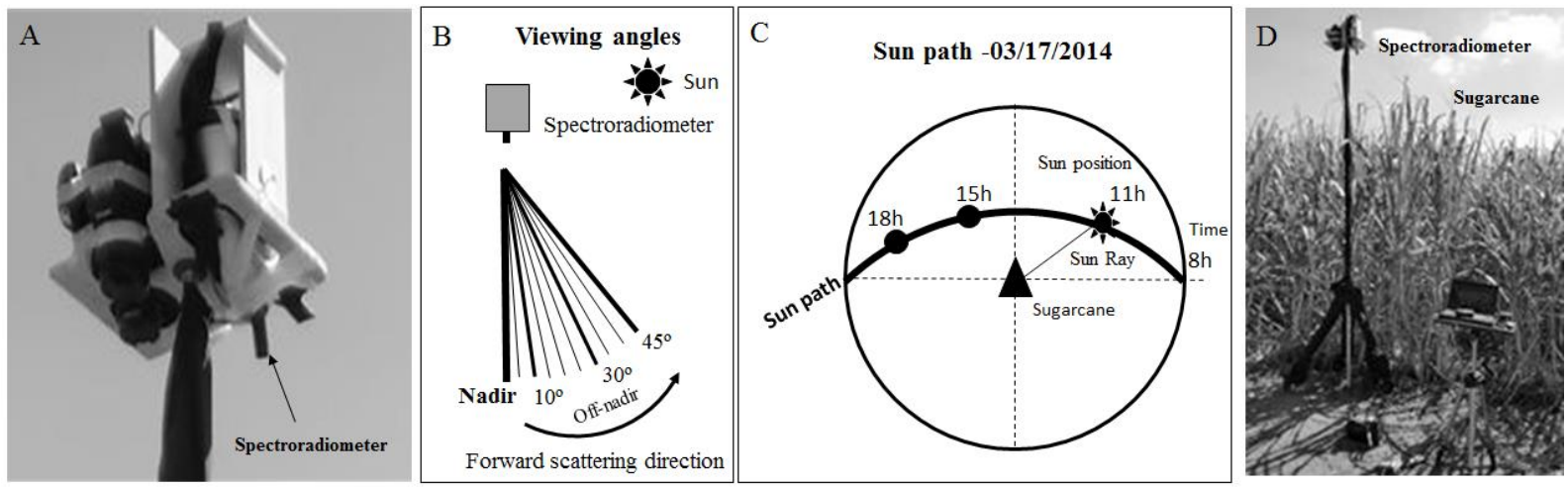

Figure 2: A) Sensors installed in the holder. B) Forward scattering direction. C) Sun path diagram 03/17/2014. D) Sensor support on canopy of sugarcane.

The support has a structure that allows the spectroradiometer to be dotted so that measurements can be made from different viewing angles, these angles being adjusted with a goniometer. Measurements were therefore taken at ten different viewing angles at forward scatter (Figure 2.B), being in nadir, and viewing angles off-nadir specifically at $5^{\circ}, 10^{\circ}, 15^{\circ}, 20^{\circ}, 25^{\circ}$, $30^{\circ}, 35^{\circ}, 40^{\circ}$, and $45^{\circ}$. Figures 2.B and 2.C show Sun path, the solar azimuth angle was $272.9^{\circ}$ with $10.43^{\circ}$ of solar elevation and $0.181^{\circ}$ of zenith angle.

As the measurements were to be performed above the canopy of the field, the support was installed on a pole supported by a tripod. Figure 2.D shows the support of this set of sensors arranged in the field. A Spectralon ${ }^{\circledR}$ plate was used to calibrate the spectroradiometer. In each sample, 10 radiance measurements were performed with the spectroradiometer and the mean spectral curve was analyzed, obtaining the estimation of the BRDF from equation 1 . For Nicodemus et al. (1977) and Schaepman-Strub et al. $(2004,2006)$ when dealing with a large area with isotropic properties and constantly irradiated, the quantity that quantifies the geometric characteristics of the target reflection properties is the BRDF or $f r$ (given in $s r^{-1}$ ):

$$
f r\left(\theta_{i}, \phi_{i} ; \theta_{r}, \phi_{r}\right)=\frac{d L_{r}\left(\theta_{i}, \phi_{i} ; \theta_{r}, \phi_{r} ; E_{i}\right)}{d L_{i}\left(\theta_{i}, \phi_{i}\right) \cdot \cos \theta_{i} \cdot d \omega_{i}}
$$

Where $i$ refers to the incident energy and $r$ to the reflected energy. $\theta$ is the zenith angle and $\phi$ is the azimuth angle, both quantified in radians, $\omega$ is the solid angle in spherorradians, $L$ refers to radiance, $E_{i}$ is the incident irradiance.

In addition, to minimize the effects of noise from the atmosphere and electronics, a moving average filter of size 10 was applied in the original BRDF spectral profile, that is, based on the average of a set of values within the given neighborhood range. In this way, the spectral reflectance profile looks smoother. After the analysis of the spectral reflectance profile, the correlation coefficient was calculated by comparing the spectral profile with each other in order to verify whether the data are correlated.

To study the spectral variability of BRDF in the data, anisotropy factor can be used (Jackson et al. 1990). Anisotropy factors (ANIF-Anisotropy factors) split the spectral signature of a target and the effects coming from BRDF. The ANIF (Equation 1 ) is calculated from the normalization of the bidirectional reflectance data of the target $R_{\text {target }}$ with the nadir reflectance, $R_{\text {target_nadir }}$, therefore is dimensionless quantity, and (Sandmeier et al. 1998; Sandmeier and Deering 1999).

$$
A N I F=\frac{R_{\text {target }}}{R_{\text {target_nadir }_{-}}}
$$


According to Liesenberg (2006), in nadir the ANIF of a surface is 1; values greater than 1 are observed for angular configurations arranged in the backscatter region and values smaller than 1 are in the forward scattering region. In addition, reflectance peaks, maximum and minimum, become more evident, allowing the identification of hot spot and cold spot.

ANIF was calculated centering the spectral bands in blue $(430 \mathrm{~nm}$ - absorption band of chlorophyll a, $450 \mathrm{~nm}$ and $480 \mathrm{~nm}$ ), green (550 nm green reflection and absorption band of phycoerythrin), $620 \mathrm{~nm}$, red $(650 \mathrm{~nm}, 660 \mathrm{~nm}$ - absorption band of chlorophyll a, and $675 \mathrm{~nm})$, near infrared (750 $\mathrm{nm}$ and $900 \mathrm{~nm})$.

Another index that estimates the anisotropy of reflectance and compares it with the effects of BRDF is the anisotropy index (ANIX). The ANIX is given by the ratio between the maximum bidirectional reflectance (Rmax) and minimum (Rmin) measured in a target (Sandmeier et al. 1998; Sandmeier and Deering 1999).

$$
A N I X=\frac{R_{\text {max }}}{R_{\text {min }}}
$$

According to Sandmeier and Deering (1999), for vegetation, the Rmax is associated with the hot spot and Rmin is near the nadir in the direction of forwarding spreading.

The BRDF model (Equation 4) developed by Walthall et al. (1985) was used to evaluate its ability to compensate the anisotropy factor in target response and minimize the effect of BRDF.

$$
R_{j k}\left(\theta_{i}, \theta_{r}, \varphi\right)\left(a^{\prime} \theta_{r}^{2}+b^{\prime} \theta_{r} \cos \varphi+1\right)
$$

Where $R k(0,0, \varphi)$ is the reflectance factor of point $k$ measured with nadir target geometry, with the zenith angle equal to zero, and azimuth angle $(\varphi)$ given by $\varphi=\varphi r$ - $\varphi$ ( reflected azimuth angles and incident). $\theta r$ is the zenithal angle of the sensor, and the coefficients a 'and b' derived from the zenithal angle of the sensor give. The azimuthal angle was obtained from the coordinates of the point where measurements were taken.

\section{Results and discussions}

Sugarcane spectral reflectance profile at different viewing angles are shown in Figure 3. Typical spectral profile of healthy green vegetation is evident, with a peak at the spectral region of green light $(550 \mathrm{~nm})$ and scattering in the spectral region near infrared. Table 1 shown de standard deviation at different viewing angles in specifics wavelength ranges. The low standard deviation (0.0008-0.01), indicates low dispersion of values therefore, measured values are close to the mean. 
Table 1: Standard deviation at different viewing angles.

\begin{tabular}{c|c|c|c|c|c|c|c|c|c|c}
\hline & & \multicolumn{8}{|c}{ Off-nadir viewing angles $\left(^{\circ}\right)$} \\
\hline $\begin{array}{c}\text { Wavelength } \\
\text { range (nm) }\end{array}$ & Nadir & 5 & 10 & 15 & 20 & 25 & 30 & 35 & 40 & 45 \\
\hline $420-440$ & 0.002 & 0.002 & 0.002 & 0.002 & 0.002 & 0.002 & $8 \mathrm{E}-04$ & 0.001 & 0.001 & 0.002 \\
\hline $450-490$ & 0.002 & 0.002 & 0.003 & 0.001 & 0.001 & 0.002 & $8 \mathrm{E}-04$ & 0.001 & 0.0006 & 0.002 \\
\hline $490-560$ & 0.012 & 0.013 & 0.038 & 0.022 & 0.024 & 0.032 & 0.01 & 0.019 & 0.0147 & 0.013 \\
\hline $630-700$ & 0.01 & 0.01 & 0.025 & 0.024 & 0.018 & 0.022 & 0.009 & 0.016 & 0.0123 & 0.01 \\
\hline $650-670$ & 0.002 & 0.002 & 0.005 & 0.003 & 0.004 & 0.005 & $1 \mathrm{E}-03$ & 0.003 & 0.0017 & 0.002 \\
\hline $700-900$ & 0.068 & 0.086 & 0.095 & 0.073 & 0.081 & 0.09 & 0.066 & 0.081 & 0.0833 & 0.086 \\
\hline
\end{tabular}

The spectral reflectance profile showed small differences in the spectral region of the visible, the biggest difference being in the near infrared. Although the viewing angles were different, the spectral signature was maintained with small changes in intensity. The increment in the zenithal angle with respect to the target causes the increase in the reflectance of the vegetation in both the visible and near infrared regions (Ponzoni and Shimabukuro 2007). Off-nadir spectral measurements were higher than those acquired at nadir in the near infrared region. Sandmeier (1998) reported that erectophile canopies produce a minimum reflectance near nadir in the forward scatter direction, sugarcane has a typical erectophile canopy. Erectophiles canopy have their leaves largely hanging vertically. But, in $30^{\circ}$ off-nadir presenter minimum reflectance factor, this results can be influence of shadow in sugarcane canopy, according to Kimes (1983) in erectophile plants is a common characteristic.

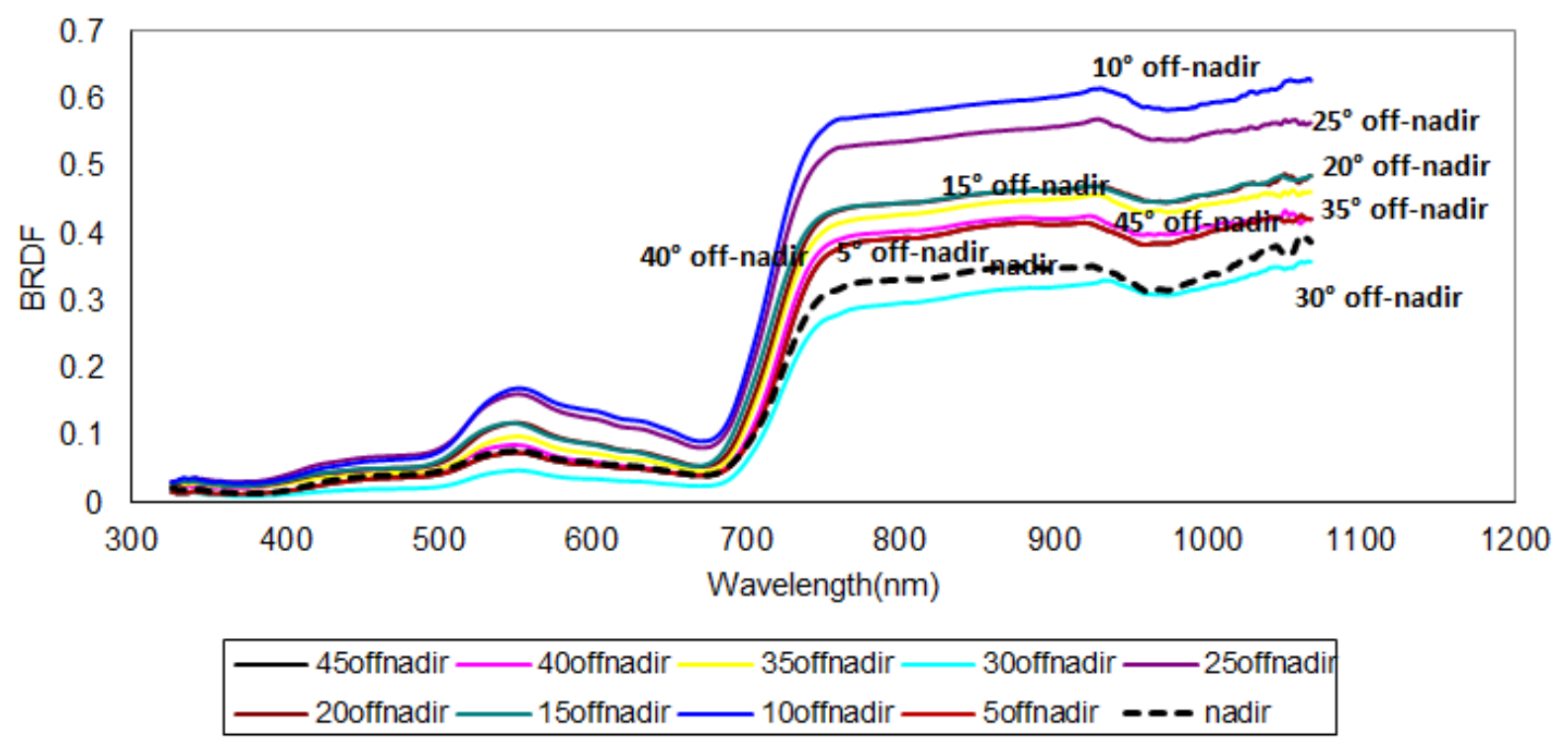

Figure 3: Bidirectional Reflectance Distribution Function of sugarcane, measured at different viewing angles.

In the near infrared spectral region, the intensity variation was higher among all the spectral reflectance profile analyzed. The highest variation of near infrared scattering could be due to the structural characteristics of the erectile sugarcane leaf. According to Galvão et al. $(2005,2006)$ erectophilic canopies suffer greater influence from shading, resulting from the canopy's own components. With the angle variation associated with canopy components (presence of shade, folded leaves, dried leaves, straws) the electromagnetic radiation may have been more spread in the near infrared region. 
This change in magnitude occurs between the red and near infrared regions. This can affect the red edge position, requiring the normalization of the responses recorded in the pixels to be taken with different acquisition geometries. This avoids the distortion of spectral data which are collected by hyperspectral cameras on Unmanned Airborne System (UAS), for instance, that are distorted by this type of change.

Pearson's correlation coefficient was used, evidencing the spectral data are highly correlated, with values ranging from 0.994 to 1 . This result indicates that the application of a similarity analysis in the form of the spectral response is possible to be realized. Such discriminant analysis does not require the application of a calibration or transformation of those spectral reflectance profiles.

The visual analysis of the anisotropy factor profile (Figure 4) enabled the identification of similar behavior in the different wavelengths, with an apparent variation in the magnitude of the spectral response, as there was variation in the viewing angle. In the visible spectral region, mainly between 300 and $500 \mathrm{~nm}$, there was no significant change in the intensity amplitude, changing mainly at $550 \mathrm{~nm}$ for the angles of 25 off-nadir and $10^{\circ}$ off-nadir.

The ANIF at the wavelength of $430 \mathrm{~nm}$ showed light variation except at the $25^{\circ}$ off-nadir angle, where a decrease in its value was observed at about 0.62 (Figure 4.A).

At the $30^{\circ}$ off-nadir angle, this same behavior of decreasing the ANIF in all analyzed wavelengths can be seen, with values lower than 1 , related, therefore, with forwarding scattering component. For wavelengths less than $750 \mathrm{~nm}$, ANIF values less than 1 were found, as well as for the $45^{\circ}$ offnadir angle. From $20^{\circ}$ off-nadir to $15^{\circ}$ off-nadir a stability in the anisotropy factor can be seen for all wavelengths.

This decrease in the variation of the ANIF may be associated with the canopy heterogeneity, because, the measurements were taken at different locations, and therefore, there could be changes in factors that masked the acquisition environment. For example, a greater influence of shading between the sugarcane leaves or wind, which in some way interferes with the response recorded by the sensor.

At the analyzed wavelengths two peaks were observed in the ANIF, that is, two effect of specular component: one located at the $25^{\circ}$ off-nadir angle and the other at $10^{\circ}$ off-nadir. At these angles, the values were greater than 1 , indicating that these angular configurations would be arranged in the backscatter region, except at the wavelength of $430 \mathrm{~nm}$ where no peak is observed at $10^{\circ}$ offnadir. It can be seen that the ANIF was higher (greater brightness) for angles greater than $25^{\circ}$ offnadir in all analyzed wavelengths. This factor is expected to increase as the slope increases, this acquisition geometry is usually avoided. Pixels are taken with these acquisition geometries, it is necessary to consider the radiometric normalization modeling.

However, it is observed that there is a low spectral variation of ANIF, which greatly facilitates a radiometric calibration of images taken from UASs, that is, pixels taken with different target geometries can be normalized to a single frame with less complex models.

Although the shapes of the spectral reflectance profile of the sugarcane were maintained, it is noticeable that the variation in the intensity can be compensated in hyperspectral images. Thus, it can be assumed that the effect of the anisotropy can be compensated in the images taken in sugarcane applying BRDF correction models. 
A

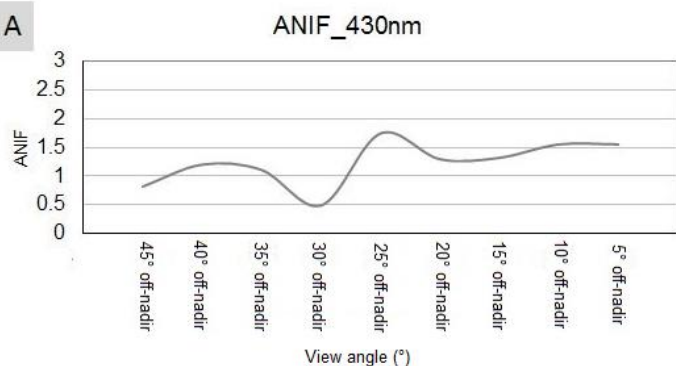

C

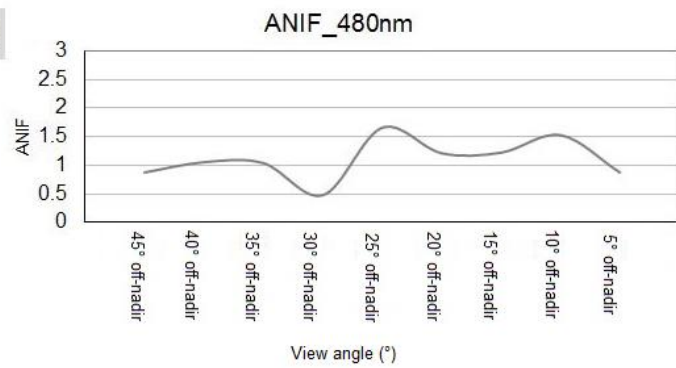

$\mathrm{E}$

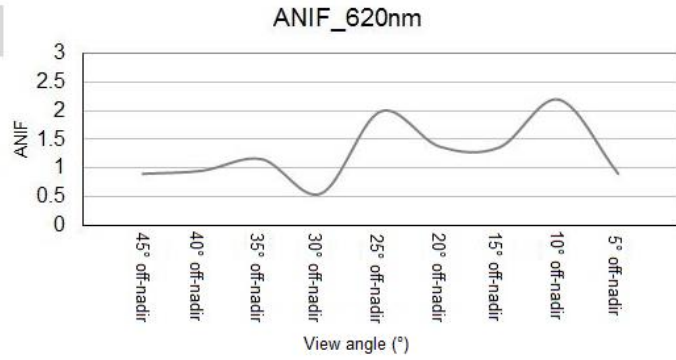

G

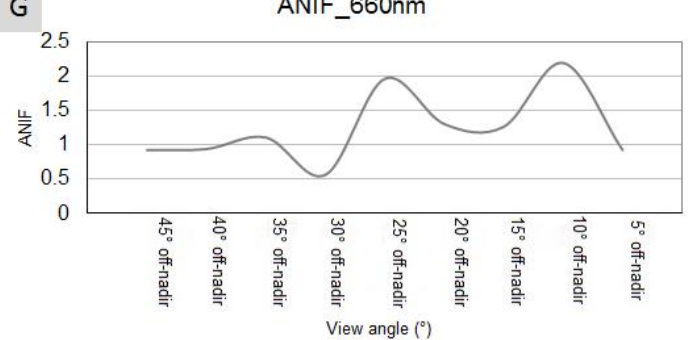

1

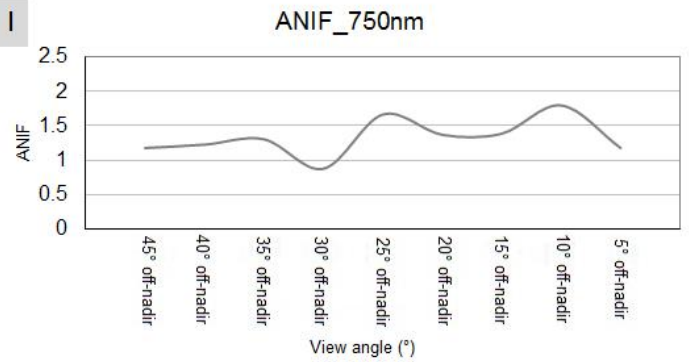

B

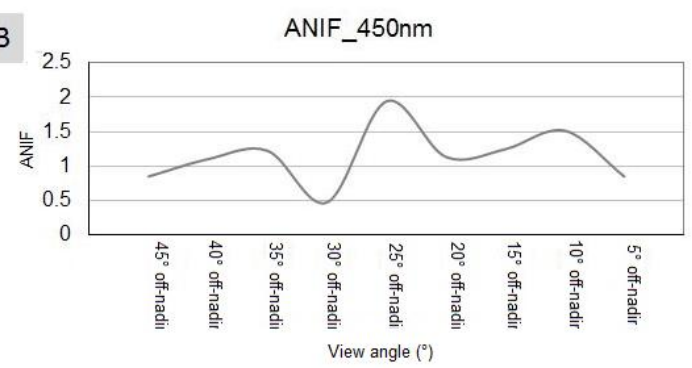

D
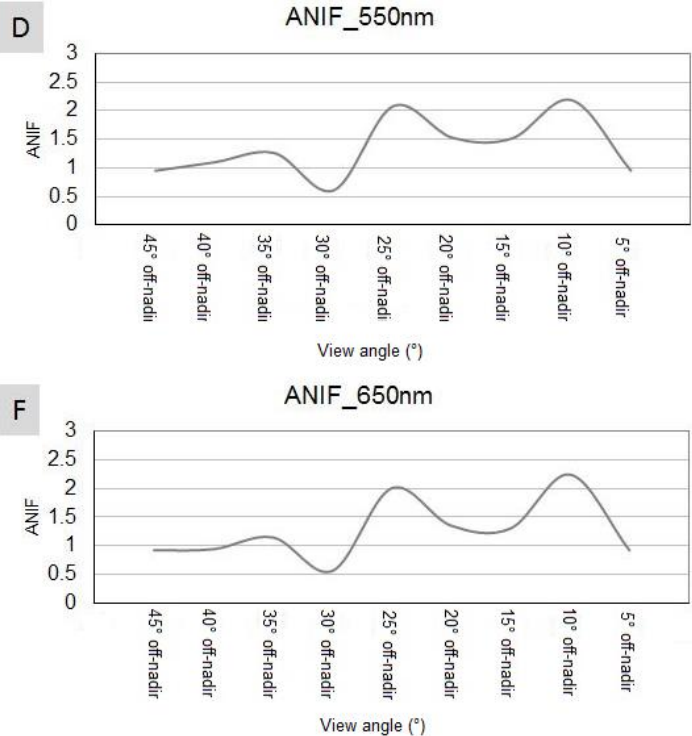

$\mathrm{H}$

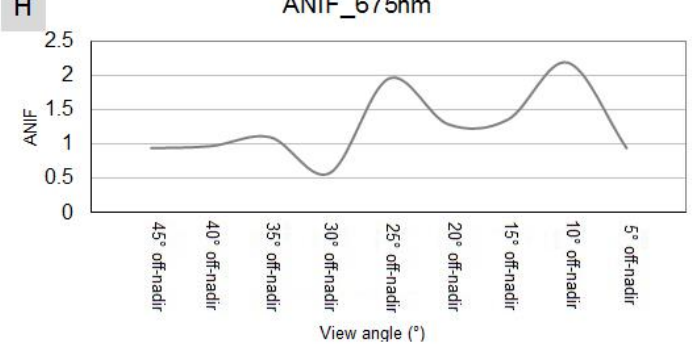

J

ANIF_900nm

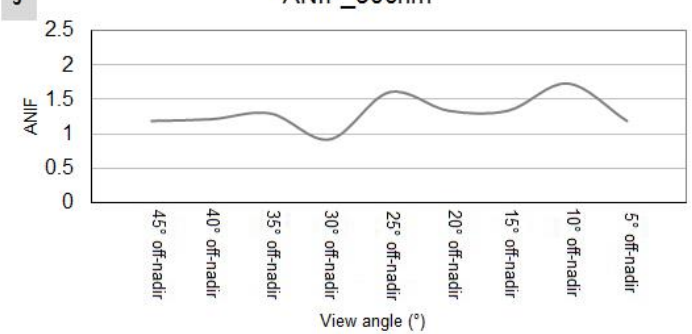

Figure 4: ANIF at different wavelengths: (A) $430 \mathrm{~nm}$, (B) $450 \mathrm{~nm}$, (C) $480 \mathrm{~nm}$, (D) $550 \mathrm{~nm}$, (E) 620 nm, (F) $660 \mathrm{~nm},(\mathrm{G}) 660 \mathrm{~nm},(\mathrm{H}) 675 \mathrm{~nm},(\mathrm{I}) 750 \mathrm{~nm},(\mathrm{~J}) 900 \mathrm{~nm}$.

The highest values of anisotropy determined by ANIX (Figure 5) occurred in the visible region. The maximum ANIX was around 4 near the $650 \mathrm{~nm}$ wavelength. The values of ANIX decreased in the near infrared, becoming almost consistent. 


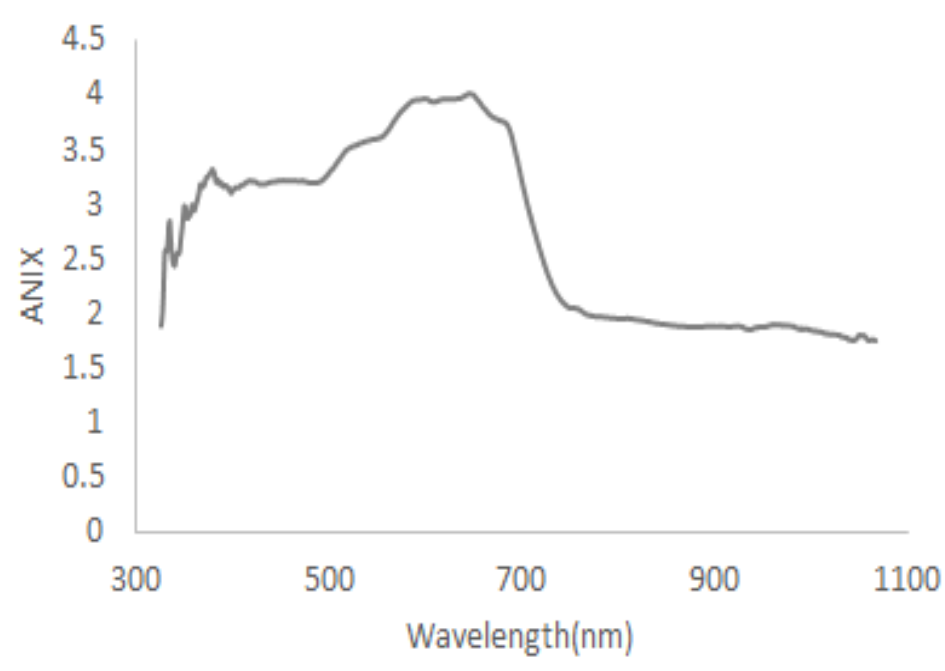

Figure 5: Anisotropy index.

The model of Walthall et al. (1985) for BRDF correction was applied to the spectral reflectance profile (Figure 6). It can be seen that there was an accentuation of features in the spectral curve with the corrected BRDF when compared with the original spectral curve (Figure 6.A).

The spectral reflectance profile measured at different viewing angles presented only a difference in their magnitude, maintaining the shape and features of the spectral curve. It was also observed that the spectral profile was closer to the curve at nadir, especially the spectral profile at the $25^{\circ}$ off-nadir, $20^{\circ}$ off-nadir, $15^{\circ}$ off-nadir and $5^{\circ}$ off-nadir viewing angles (Figure 6.B). The spectral reflectance profile with off-nadir angles of $45^{\circ}, 40^{\circ}, 35^{\circ}$ and $30^{\circ}$ were also close together.

The result obtained in this work reveals that spectra taken from extreme viewing angles should be avoided as their correction may be more difficult. The set of spectra that approached the nadir response indicates that a preliminary correction of this type may be a suitable treatment for spectral data from the sugarcane crop. 


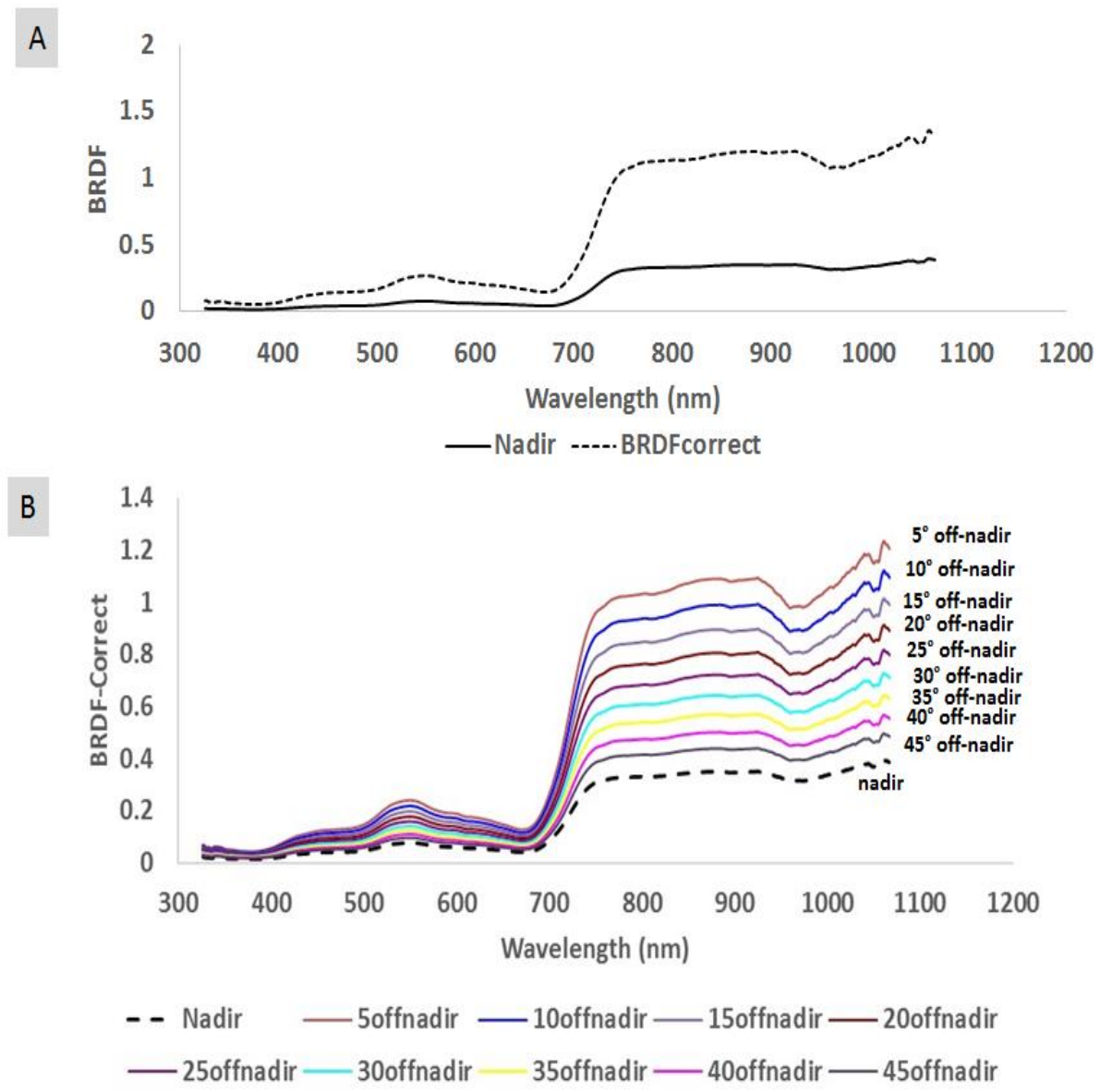

Figure 6: (A) Comparison between spectral reflectance profile with and without application of Walthall's BRDF correction model. (B) Spectral reflectance profile at different viewing angles applied to Walthall's BRDF correction model.

\section{Conclusions}

The experiments carried out in this work showed that the variation in the viewing angle influences the HCRF, with the spectral signatures presenting similar forms, varying mainly in magnitude, with greater effect in the near infrared region. This variation between the visible and near infrared regions causes a change in the angle of inclination of the spectral curve between these two regions. Consequently, the shape of the spectral curve suffers a greater degree of alteration in this spectral range. However, as it is a local change, it does not affect the similarity of the spectra taken in different geometries. This result was confirmed by the analysis of Pearson's correlation coefficient, where the values were high. The high correlations show that the answers have coherence.

The anisotropy factor demonstrated showing an approximately similar behavior at all wavelengths, as well as in the visual analysis of the spectral reflectance profile of the sugarcane, only being observed variation in intensity at the different viewing angles.

From the results obtained in the experiments, with the variation of the spectral curve in the amplitude of its intensity, it is possible to correct these BRDF variations in magnitude using the acquisition geometry in the image processing, based on the radiometric calibration. Using 
appropriate models, such Walthall et al. (1985), which was applied in this experiment, reduced the effects of BRDF on the spectral reflectance profile, bringing the spectral profile close to nadir. Image calibration approaches such Honkavaara et al. (2013), who use the model of Walthall et al. (1985) for the treatment of hyperspectral images in Precision Agriculture, may be a satisfactory alternative for the case of sugarcane crop.

\section{ACKNOWLEDGEMENT}

The authors are thankful to FAPESP (Fundação de Amparo à Pesquisa de São Paulo) for funding part of this research (2013/50426-4) and CAPES for a PhD scholarship. The authors also thanks the Ruette Agroindustrial Group, Monte Rey Unit, in Ubarana for their important support in the collection of radiometric measurements in the field, especially Rosiane de Souza, corporate manager of human resources, Leonardo Augusto Camargo and Fabrício Benaducci. Gabriela Takahashi Miyoshi and Marcus Moraes for their support in the field campaigns.

\section{REFERENCES}

Ahamed, T. et al. 2011. A review of remote sensing methods for biomass feedstock production. Biomass and bioenergy, 35, pp. 2455-2469.

Deering, D. W.; Middleton, E. M.; Eck, T. F. 1994. Reflectance anisotropy for a Spruce-Hemlock forest canopy. Remote Sensing of Environment, 47, pp. 242-260.

Galvão, L. S.; Formaggio, A. R.; Tisot, D. A. 2005. Discriminação de variedades de cana-de-açúcar com dados hiperespectrais do sensor Hyperion/EO-1. Revista Brasileira de Cartografia, 57 (01), pp. 7-14.

Galvão, L. S.; Formaggio, A. R.; Tisot, D. A. 2006. The influence of spectral resolution on discriminating Brazilian sugarcane varieties. International Journal of Remote Sensing, 27, pp. 769777. DOI: 10.1080/01431160500166011.

Honkavaara, E. et al., 2012. Hyperspectral reflectance signatures and point clouds for precision agriculture by light weight UAV imaging system. In: ISPRS Annals of the Photogrammetry, Remote Sensing and Spatial Sciences, XXII ISPRS Congress, 25 august-01 september. Melbourne: ISPRS Annals of the Photogrammetry, Remote Sensing and Spatial Sciences, I-7, pp.353-358.

Honkavaara, E. et al. 2013. Processing and assessment of spectrometric, stereoscopic imagery collected using a lightweight UAV Spectral Camera for Precision Agriculture. Remote Sensing, 5, pp. 5006-5039.

Instituto Nacional De Pesquisas Espaciais (Inpe). 2014. Mapeamento da cana via imagens de satélite de observação da Terra. Available at: <http://www.dsr.inpe.br/laf/canasat/> [Accessed october 2013\}.

Jackson, R. D. et al. 1990. Bidirectional measurements of surface reflectance for view angle corrections of oblique imagery. Remote Sensing of Environment, 32, pp. 189-202.

Kimes, D. S.; Smith, J. A.; Ranson, K. J. 1980. Vegetation reflectance measurements as a function of solar zenith angle. Photogrammetric Engineering and Remote Sensing, 46, pp.1563-1573. 
Kimes, D. S. et al. 1985. Directional reflectance factor distributions for cover types of Northern Africa. Remote Sensing of Environment, 18, pp. 1-19.

Liang, S. 2004. Quantitative Remote Sensin of Land surfaces. New Jersey: John Wiley \& Sons, 534 p.

Liesenberg, V. 2006. Análise multi-angular de fitofisionomias do bioma cerrado com dados MISR/TERRA. Dissertação de mestrado do Curso de Pós-graduação em Sensoriamento Remoto. INPE: São José dos Campos.

Lofton, J. et al. 2012. Estimating sugarcane yield potential using an in-season determination of normalized difference vegetative index. Sensors, 12, pp. 7529-7547.

Milton, E. J.; Webb, J. P. 1987. Ground radiometry and airborne multispectral survey of bare soil. International Journal of Remote Sensing, 8, pp. 3-14.

Nicodemus, F. E. et al., 1977. Geometrical Considerations and nomenclature for reflectance. Washington: U.S. Department of Commerce.

Ponzoni, F. J.; Shimabukuro, Y. E. 2007. Sensoriamento Remoto no estudo da vegetação. São José dos Campos: Parêntese. (ISBN 978-85-60507-02-3)

Robinson, B. F.; Biehl, L. L. 1982. Calibration procedures for measurement of reflectance factor in Remote Sensing Field research. LARS Technical reports, paper 93. Machine processing of Remotely Sensed data Symposium, pp. 435-440.

Rudorff, B. T et al. 2010. Studies on the rapid expansion of sugarcane for ethanol production in São Paulo State (Brazil) using Landsat data. Remote Sensing, 2, pp. 1057-1076.

Sandmeier, S. R. et al., 1998. Physical mechanisms in hyperspectral BRDF data of grass and watercress. Remote Sensing of Environment, 66, pp. 222-233.

Sandmeier, S. R.; Itten, K. I. 1999. A field goniometer system (FIGOS) for acquisition of hyperspectral BRDF data. IEEE Transactions on Geoscience and Remote Sensing, 37, pp. 978-986.

Sandmeier, S. R..; Deering, D. W. 1999. Structure analysis and classification of boreal forest using airborne hyperspectral BRDF data from ASAS. Remote Sensing of Environment, 69, pp. 281-295.

Sandmeier, S. R. 2000. Acquisition of bidirectional reflectance factor data with field goniometers. Remote Sensing of Environment, 73, pp. 257-269.

Schaepman-Strub, G. et al. 2004. About the importance of the definition of reflectance quantitiesresults of case studies. In: Proceedings of the XXth ISPRS Congress, pp. 361-366

Schaepman-Strub, G. et al. 2006. Reflectance quantities in optical remote sensing - definitions. Remote Sensing of Environment, 103, pp. 27-42.

Unica. União da indústria de cana-de-açúcar. 2008. Available at: <http://www.unica.com.br/content/show.asp?cntCode=9E97665F-3A81-46F2-BF69-

26E00C323988> [Accessed October 2008].

Walthall, C.L. et al. 1985. Simple equation to approximate the bidirectional reflectance from vegetative canopies and bare soil surfaces. Applied Optics, 24, pp. 383-387.

Weyermann, J. et al. 2014. Correction of reflectance anisotropy effects of vegetation on airbone spectroscopy data and derived products. IEEE Transactions on Geoscience and Remote Sensing, 52, pp. 616-627. 